\title{
Learning Environments Research Role of technology in the design of learning environments --Manuscript Draft--
}

Manuscript Number:

Full Title:

Article Type:

Keywords:

Corresponding Author:
LERI-D-19-00196R2

Role of technology in the design of learning environments

Manuscript

Co-design, learning environments, participatory design, technology-enhanced learning

Diogo Casa Casanova, Ph.D

University of West London

Ham, Richmond, Surrey UNITED KINGDOM

Corresponding Author Secondary Information:

Corresponding Author's Institution:

University of West London

Corresponding Author's Secondary Institution:

First Author: Diogo Casa Casanova, Ph.D

First Author Secondary Information:

Order of Authors:

Diogo Casa Casanova, Ph.D

Isabel Huet, PhD

Fabiane Garcia, PhD

Teresa Pessoa, PhD

Order of Authors Secondary Information:

Manuscript Region of Origin:

Europe

Funding Information:

\section{Abstract:}

The design of learning environments is being increasingly investigated, largely as a result of higher-education providers being challenged by both societal and technological developments. These providers are becoming more aware that the quality of learning environments affects students' approaches to learning and satisfaction. This paper presents an alternative to more-traditional methods for designing learning environments that is driven by input of their main stakeholders: students and teachers. By using this method, we were able to explore stakeholders' insights into learning spaces design and how learning technologies can be integrated in such spaces. Qualitative research was conducted with the aim of guiding the redesign of technology-enhanced learning environments. For this particular research, we used 'sandpits', which are creative and design-thinking workshops, in which participants are encouraged to redesign provocative concepts of a large and a small technology-enhanced learning environment. Thirteen 'sandpits' were delivered involving 32 teachers and 25 students. Through these design-thinking workshops, students and teachers reflected on and discussed the role of technology in face-to-face learning and teaching and proposed new design solutions for technology-enhanced learning environments.

\section{Response to Reviewers:}

The authors would like to thank reviewer 1 for providing again important suggestions to improve the quality of the manuscript. We carefully analysed them and tried to improve each section based on the suggestions. We present below how we addressed each recommendation.

-The two concepts used (cube and poppy flower), I wonder how detailed the instructions were the participants got. Did they just get some main/general characteristics explained of each concept? Or did they basically get a prototype, e.g. 
description including figures such as presented in the manuscript? If the former was the case, the participants basically could start from a more open setup than in case of the latter, where they basically already had a prototype, that they could delete stuff from or add stuff to. For me, this is quite crucial, as I explained in my initial review, I feel that a more 'closed' start - and I strongly get the feeling this was indeed the case leads to potentially quite different outcomes than a more open approach, in which participants only get some basic assumptions. Or, to put it differently: what you put in is what you get out of it!

We've have added a new paragraph to improve readability and clarify how open the redesign process was. We also made changes in the Discussions to provide more insight into the approach taken.

"Importantly, learning space concepts were given as a framework to foster discussions and redesigns not as a close prototype. Thus, results from engaging with this process resulted in very different outputs from 'sandpit' to 'sandpit'."

-I feel this also needs to discussed more in the final section of the manuscript. Rather than provide more 'technical/material' implications such as on projector screens, BYOD, etc., rather provide more discussion on the approach. What might happen if you had participants work with less contrasting prototypes? What would happen if you had provided them with less information, or a less worked-out prototype to start from? Also, what are advantages of this approach to the (re)design process for learning environments.

We have made changes by removing recommendations about learning technologies ('technical/material' implications such as on projector screens, BYOD, etc.) and by introducing more discussions about the approach used. We were limited by the already existing length of the text so we were unable to cover all of what was suggested but still we included a new section in the last section.

"We used 'Sandpits' and the possibility of redesigning learning environments as a tool to promote discussion about the role of learners and teachers in the teaching and learning process. The openness of the process which started with a common design framework, based on the presentation of the concepts and the narrative, and finished with very different outputs, suggest that how participants see the learning environment design diverges according to their own individual views, which are informed by their own disciplinary practices, personal identities and institutional context. Therefore, it is conceivable that the outcomes of the research may be different if participants are originated from a different $\mathrm{HE}$ sector or from a specific discipline. However, being able to redesign a new environment based on a common framework was an opportunity for staff to engage in a creative grassroots process which would not happen if they have started with a finished prototype.

Acknowledging the value of this method for redesigning learning environments, we recognise that its blue-sky thinking approach is more suitable for a first iteration of the design process and as a way to engage stakeholders in thinking about their role in learning and teaching. Equally, it may be a useful tool to generate new and creating learning environments more suitable for the 21 st century pedagogy. In a second iteration it is important to involve IT, estates and architects to evaluate what is achievable and sustainable."

I would suggest to rename the final section into 'discussion', rather than 'final considerations'.

We have changed from Final considerations to Discussions

For example, the fact that teachers are more critical to technologies and students are more optimistic is found all over literature on this topic. Also, where does the 
implication for more training come from, it helps if you could tie this to specific results/findings/impressions from the data

We included two new sections: one in the Introduction and one in the Discussions section

This is particularly relevant as research has been suggesting different perceptions of the value of learning technologies between staff and students with the former being more critical and with difficulty of understanding the pedagogical value of using learning technologies and the latter often more enthusiastic and open for innovation (Blin and Munro 2008; Waycott et al. 2010).

These findings are important to discuss as they highlight levels of criticality from staff in relation to the use of learning technologies particularly in relation to its pedagogical value. This suggests that we should provide more guidance and pedagogical training to support staff on how to make the best use of learning technologies in the classroom (Beichner et al. 2000; van Merriënboer et al. 2017). Equally, we provide findings about assumptions that students are always enthusiastic with all learning technologies which, based on the data we found, not always is the case, for example with BYOD for learning. Better understanding of students and staff view about learning technologies in the classroom will allow more informed decisions and more relevant use of learning technologies in the design of learning environments (Henderson et al. 2017; Waycott et al. 2010). 
Role of technology in the design of learning environments

LERI-D-19-00196R2

Diogo Casanova ${ }^{\text {a }}$, Isabel Huet ${ }^{\mathrm{a}}$, Fabiane Garcia ${ }^{\mathrm{c}}$ and Teresa Pessoad

Corresponding author: Diogo Casanova $(\square)$

${ }^{a}$ Diogo Casanova and Isabel Huet

ExPERT Academy

University of West London

St Mary's Road

London, W5 5RF, UK

Tel: $\quad+44(0) 2082094279$

Email: diogo.casanova@uwl.ac.uk;

https://orcid.org/0000-0002-8586-0370

${ }^{\mathrm{c}}$ Fabiane Garcia

Universidade Federal do Amazonas

Instituto de Ciências Exatas e Tecnologia Manaus

AM, 69067-005

Brasil

${ }^{\mathrm{d}}$ Teresa Pessoa

Faculdade de Psicologia e de Ciências da Educação

Universidade de Coimbra

Coimbra

Portugal 


\title{
Role of technology in the design of learning environments
}

Submitted: 29 October $2019 \quad-\quad$ Accepted:

\begin{abstract}
The design of learning environments is being increasingly investigated, largely as a result of higher-education providers being challenged by both societal and technological developments. These providers are becoming more aware that the quality of learning environments affects students' approaches to learning and satisfaction. This paper presents an alternative to more-traditional methods for designing learning environments that is driven by input of their main stakeholders: students and teachers. By using this method, we were able to explore stakeholders' insights into learning spaces design and how learning technologies can be integrated in such spaces. Qualitative research was conducted with the aim of guiding the redesign of technology-enhanced learning environments. For this particular research, we used 'sandpits', which are creative and design-thinking workshops, in which participants are encouraged to redesign provocative concepts of a large and a small technology-enhanced learning environment. Thirteen 'sandpits' were delivered involving 32 teachers and 25 students. Through these design-thinking workshops, students and teachers reflected on and discussed the role of technology in face-to-face learning and teaching and proposed new design solutions for technology-enhanced learning environments.
\end{abstract}

Keywords: Co-design, learning environments, participatory design, technology-enhanced learning 


\section{Introduction}

Until recently, learning environments have been designed based on the traditional paradigm of row-by-row seating, with the teacher positioned on a podium at the front and facing a substantial number of students with the role of 'transmitting' knowledge (Beichner 2014). In this type of layout, the teacher becomes the focal point at the front of the room and this conveys an implicit message of power, with the teacher having the entitlement to speak, whereas the students listen in a passive and non-participatory manner (Van Note Chism 2006).This layout is still arguably the most-commonly used in universities today, and it runs counter to the participatory nature of learner-centred pedagogies (Jessop et al. 2012). It is argued that, with higher-education (HE) institutions increasingly supporting active and learner-centred pedagogies, more-flexible learning spaces need to be created. In order to respond to such challenges, HE institutions have been designing new and more technologically-enabled spaces. New spaces are often based on a cabaret-style teaching layout (with rounded or squared tables), with different screens to visualise information, devices to interact with the classroom and aiming to achieve the objective of promoting collaborative and active learning pedagogies (Beichner 2014; Jessop et al. 2012; Mei and May 2018). These arguments are based on research that suggests that the design of a learning environment has an influence on how its users conceptualise pedagogical practice and therefore, by changing the layout and technology of the learning environment, we can create a change in how users behave in that learning environment (Beichner 2014; Crook and Mitchell 2012; Jamieson et al. 2000; Jessop et al. 2012; Park and Choi 2014; Verdonck et al. 2019).

However, although Mei and May (2018) report that teachers can be encouraged to change pedagogy and experiment with new learning strategies when teaching in a 
Technology-Enhanced Learning Environment (TELE), they are also less positive in regards to specific technologies, even when trained to use them. Notably, in this research, the authors found that the document camera, classroom iPad sets and Extron screen consoles (control pads) were neither useful nor user-friendly and had a negative impact on how teachers were teaching. They concluded that technology in learning environments should be easy to use, reliable, and pedagogically relevant (Mei and May 2018). Likewise, large-scale research undertaken in two HE institutions in Australia reported students-perceived 'usefulness' of digital technology in university teaching and learning (Henderson et al. 2017). The authors found that students tend to assign more importance to technology when it helps them to organise and manage the logistics of studying and enables them to access information from everywhere. Fewer references were made to technology in-classroom to augment learning or to promote collaboration, engagement, interaction or deeper learning. Technology in learning environments is not augmenting learning because of its lack of perceived relevance and nonsophistication in the traditional dynamics of the learning and teaching process (Baepler et al. 2014; Henderson et al. 2017; Sheppard et al. 2008; Verdonck et al. 2019). It is important, therefore, to evaluate users' perceptions of the role and value of technologies in learning environments design. This is particularly relevant because research suggests that perceptions of the value of learning technologies differ between staff and students, with staff being more critical and having difficulty in understanding the pedagogical value of using learning technologies and students often being more enthusiastic and open for innovation (Blin and Munro 2008; Waycott et al. 2010).

Until recently, HE research has not concerned itself much with the design of learning environments; however, this has been changing in the last decade, perhaps because of an increased need to provide better and more pedagogically-sound learning environments (Beichner 2014; Temple 2008). Although learning environment design research has been 
growing, little reference has been made in the literature to how to involve stakeholders in this process and how to use the data collected to inform estates, IT services and architects.

In this paper, we present a user-centred perspective for researching TELE by focusing on how students' and teachers' perceptions of these environments can contribute to their actual design in agentic ways and how technology can be integrated in a more-effective and -useful way. We believe that, by promoting this form of grass-roots engagement, universities might be able to promote the construction of TELE that are meaningful to their users' practices (Bligh 2014) and use technology to augment learning opportunities and the learning process. Furthermore, the opportunity to conduct research into the design process could generate important insights into how students and teachers perceive learning technologies in the learning process and how these perceptions, in turn, can be used in the design of learning environments.

We discuss the purpose and value of technologies in learning environments by redesigning a large (the 'Cube') and a small (the 'Poppy Flower') TELE. We wanted to explore how both students and teachers would redesign these environments and how they would use technology to respond to different challenges of space design.

\section{Research design and methods}

The research took place in a medium-to-large teaching-focused university located in the South East of England. The university has a strong teaching ethos and clear references in its educational vision to more-active and -participative learning. At the time of the research, the majority of its classrooms had traditional row-by-row seating layout. The majority of the rooms are equipped with a document camera, a screen console, one or more projector screens (depending on the size of the room) and a few sockets in the floor for charging laptops and 
computers. Wireless Internet is available across campus and widely used by all students using the eduroam network. The university offers degrees in different disciplines to students with a wide range of backgrounds.

A sample of students and teachers was chosen and contacted by e-mail. We tried to have a full representation of disciplines, genders and years of study, which was widely achieved. 25 students aged 19 to 35 years, across different disciplines (11 from STEM; 7 from Social Sciences; 5 from Arts and Humanities; 2 from Allied health), and 32 teachers, also across several disciplines (14 from STEM; 11 from Social Sciences; 2 from Arts and Humanities; 5 from Allied health) and at different stages of their careers, agreed to participate in the study. Because we were conscious that teachers' voices could supress students' voices during discussions, the 'sandpits' were organised for either students or teachers. Thirteen 'sandpits' were conducted with the intention of redesigning a learning environment concept, either for a large-group teaching scenario ( 8 'sandpits' - 5 with teachers and 3 with students) or for a small-group teaching scenario (5 'sandpits' -2 with teachers and 3 with students). The reason for uneven numbers for each of the scenarios was that, as part of the invitation, participants were asked to choose which scenario they would like to design, either a large or a small learning environment, and this resulted in a larger number of participants choosing to design the 'Cube'.

In this research, we used a participatory design to collect the data. Whilst participatory design was created initially in a socio-political context to help manage discussions between employers and unions, its use has been extended to many other user populations such as children (Frauenberger et al. 2011), adults and senior learners (Frohlich et al. 2014). When end-users are involved in designing products and services, these become more usable, scalable and sustainable (Fishman 2013). Additionally, these users become immersed in the experience of producing a meaningful concept, which gives them a sense of belonging and 
participation. Participatory design was also chosen as the data-collection method (Bonsignore et al. 2013; Cerratto-Pargman et al. 2012; Craft 2013; Ebner et al. 2010; Janssen et al. 2017; Könings et al. 2014; Mäkelä and Helfenstein 2016) as it is a means of collecting participants' perceptions, owing to the level of engagement and immersion that they face when involved in this process.

We used 'sandpits' (Frohlich et al. 2014), which are creative, design thinking workshops in which participants, stimulated by a storytelling technique and design themes, are encouraged to redesign proposed concepts, thereby contributing rich data that could inform future design briefs. An experience of participatory design is provided by Craft (2013), who used this method to solve problems with regard to technology-enhanced learning (TEL) design, including the design of new software and the re-engineering of existing TEL systems. Craft (2013) introduced sketch-in, an activity that leverages the value of freehand sketching for creativity and problem solving. He advocates that this approach supports individual reinterpreted cycles of generating ideas and enhances access to new ideas for individuals and groups.

To illustrate how the learning space concept was designed and how a lecture would take place in such a space, a storytelling technique was used (Muller 2007). Storytelling enables researchers to create real-life scenarios that give a sense of authenticity to the concepts. This gave the participants the opportunity to reflect not just on the design themes, but also on how they would engage with the space in a real-life scenario, and how they might use technology to enhance this experience. Importantly, learning space concepts were given as a framework to foster discussions and redesigns rather than as a close prototype. Thus, results from engaging with this process resulted in very different outputs from 'sandpit' to 'sandpit'. 
Each 'sandpit' had a maximum duration of one hour and was divided into the following steps:

i. The concept was presented to participants using a storytelling technique. Explanations were given of what it might mean to be involved in learning and teaching in the 'Cube' and the 'Poppy Flower'. Simultaneously, the narrator presented images of the layout of each concept, showing details of the layout, furniture and technological features. Whilst listening to the narrative each individual participant was asked to write on sticky notes what features they would like keep, lose or change in the learning environment.

ii. Participants then had time to discuss the learning environment. They were then asked again, but now as a group, what they would keep, lose or change (Casanova, Di Napoli, and Leijon 2018; Frohlich et al. 2014). This was done at the moment when they had merged some of their main individual sticky notes onto an A3 sheet of paper on which all participants' perceptions were grouped after the discussions. This task allowed them to initiate a redesign process by positioning themselves as a group. The A3 sheet and sticky notes helped participants to express their thoughts.

iii. Participants redesigned the learning space concept according to what had emerged from the discussions. At each design table, participants had at their disposal 30 photographs of design furniture and technological solutions from existing learning environments. These aimed to provide new frames of thinking for those who might have been feeling unprepared. Scissors, coloured pencils, markers and a flipchart were also available. The idea was to replicate a design environment. Participants then attempted to redesign the concept, bringing together their own critique of the existing concept, with some of the 
furniture and technological solutions found in the photographs and some ideas generated during the discussions. The output of the design was open to participants' ${ }^{\prime}$ own shared understanding of the value of a learning environment and how they would behave in such an environment. No restrictions were made in terms of size, layout or technology. This activity culminated with the group giving a different name to the concept which represented how they saw their redesigned space.

Data from the 'sandpits' were collected by the researchers using the individual sticky notes, sketches made by participants, field notes taken by the researchers and audio recordings. Each 'sandpit' was audio recorded to allow a better contextualisation of each design decision made. All data was anonymised and subsequently analysed using NVIVO9 software. The empirical data were collected and analysed respecting all ethical requirements, anonymity and data confidentiality. The data were categorised based on an inductive thematic analysis in which 10 themes emerged, three of which about the role of technology in learning environments. A professional designer later improved the sketches drawn during the 'sandpits' so that different details and relevant decisions could be presented explicitly in each final sketch.

For this research, we designed two learning environment concepts aimed at generating and collecting contrasting opinions about different aspects of the learning environment, such as the dynamics of the teaching and learning process, the size and seating, the teachers' position or the role of technology in the environment. The design of the two learning environments was informed by new trends in designing TELE (Barrett, Zhang, Moffat, \& Kobbacy, 2013; Beichner, 2014; Boys, 2011; JISC, 2006). The 'Cube' concept (Figures 1 and 2) refers to a large lecture theatre with 376 seats where the teacher is seated in the middle, in the 'box', and the students surround the teacher. 
Figures 1 and 2 about here

Although presented as a large and teacher-centred environment, the 'Cube' was designed to enhance interactivity and engagement, allowing students to interact with the lecturer using seven-inch tablet devices embedded in their tables. The content in each tablet was customised according to students' university ID so that they could get all of the learning content from the tablet, ensuring better access to the learning content in the VLE and seamless connection with the online materials. The teacher did not have a conventional podium but a table-top touch screen, which was used for managing the slides and the projector screen, monitoring students' tablets and managing the room ambience. The room had four big projector screens on top of the 'box' (the stage where the teacher was placed). These projectors faced each of the four stands, allowing students to have a clear view of the podium and the teacher even if the teacher's back was facing them. In the narrative of the 'Cube', there is an implicit message that the teacher is the centrepiece of the room.

The 'Poppy Flower' concept (Figure 3 and 4) refers to a small TELE with some similarities to the ones suggested by Beichner (2014) as part of the SCALE-Up project at the University of South Carolina. It was developed to encourage collaboration and more-active learning pedagogies.

Figures 3 and 4 about here

The room has 24 seats, although only 20 are designated for students, because each table has one seat dedicated to the teacher. The room is designed to encourage group work and the use of tangible technologies to access content and promote interaction. Each table has 
one large table-top touch screen, which enables students to work in groups and share what they are doing on one of the four circular projector screens located in the middle of the room. The teacher, via a 10-inch tablet, controls the projector screens. The teacher can project the work of one or all four tables at the same time. In each individual seat, students have their own power outlet for personal mobile devices and laptops. A Bluetooth connection can be used to ensure communication between personal devices and the table-top touch screen. There also is a breakout area (with beanbags and sofas) where students, or an external audience, can sit for more informal discussions. The 'Poppy Flower' narrative aims to lead participants to imagine a student-centred learning environment.

\section{Findings}

The results from each design session were diverse according to the dynamics that emerged during the discussions of each concept. During the 'Cube' redesign process, discussions were more conceptual, especially from teachers, who were not convinced of the benefits of teaching in such a large room and commented on how dependent the room was on learning technologies. The redesign of the 'Poppy Flower' was very much driven by detail and discussions about the benefits of table-top tablets and projector screens. This could be partly because the 'Cube' design is very provocative, suggesting that the teacher is in the middle of the room with her/his back to one quarter of the stands, and partly because of the capacity of the room, which suggests that managing the group and introducing active learning are difficult tasks.

The focus on the technology was more conceptual and thought provoking in the large lecture room, perhaps because participants were trying to find ways that technology could help to mitigate the challenges faced by the odd arrangement of the 'Cube'. In the 
majority of the redesigns of the 'Cube', the redesign outcome made the room smaller and more conducive to active learning, but the exception was the 'Spheredome' in teachers' sandpit 1. Clinton and Wilson (2019) provided similar evidence that students value activelearning classroom as being much better suited to collaborative learning.

The emphasis given to learning technologies in both concepts suggested deep discussions about the role of technologies in learning environments. For this paper, we decided to present specifically the three main themes associated with technologies that emerged from the data analyses: visualisation, personal mobile devices and how technology can be used to support student participation in the lecture (Interaction and collaboration). The other themes that emerged are presented in Casanova et al. (2018).

Table 1 about here

Visualisation

Visualisation is becoming an integral part of learning environments design, because it provides an alternative to the traditional communication channel of speaking and listening. The use of MS PowerPoint slides or similar presentation software and videos and the projection of images are almost inevitable, and there was a common sense from both students and teachers that a lecture in HE is not effective without the support of a visual presentation of some sort (James et al. 2006). In both concepts, we placed projector screens in the middle of the room (Figures 2 and 4) albeit with different shapes (square and curved formats). We also built into the design of the 'Cube' the use of multiple, simultaneous channels, thus allowing the teacher to combine a slide presentation with a tweet chat or the visualisation of an object. 
The novelty of the projector screen formats and locations was a topic for discussion because they were considered to be a valuable add-on for traditional classrooms. There was a sense within the groups that the existing solutions do not encourage engagement because they are usually small, the image has poor quality and it is often affected by external light. The general feedback from the 'sandpits' revealed that the size of the projector screens was an important factor and that the quality of the projected images and sound when listening to multimedia files influences students' engagement. The use of projector screens that were placed higher up was praised because this enabled everyone in the room to have a similar visualisation experience. Suggestions were made that more screens fixed on the walls would ensure that everyone would have the best possible experience because this would respond to the lack of visibility caused by either the brightness of the sun or the angle of the screen. This solution has been explored in terms of different learning environments, especially in computer-laboratory and technology-enabled rooms (e.g. see the rooms proposed by Beichner et al. 2000; Mei \& May 2018; Verdonck et al. 2019), but little research has explored the impact that visualisation has in learning.

Finally, there were some bold suggestions about visualisation, including the possibility of using cylindrical screens to provide a sense of immersion in the classroom (the 'Spheredome' in teachers' sandpit 1), the 'use of holograms or alternative reality' (the 'Hollodock' in teachers' sandpit 6) and the combination of social media with PowerPoint or with the projection of the teacher's face (the 'Dome' in students' sandpit 2). A group of students suggested that they would take the projectors out from the room so that the tablets in each table would act as receivers and students would be able to raise them using a moveable dock station, like a flexible arm, to improve our view (the 'Pizza Room' students' sandpit 5). 
Interaction and collaboration

Both concepts were designed to provide the strong message that, by using technology, the learning environments would enhance learners' engagement through interaction and collaboration. Throughout the storytelling phase, suggestions were made about using learning technologies to support electronic voting and a twitter-chat channel and to allow for the projection of the ongoing work from the touch screen device to the main projector screens. Rooms were also designed with furniture and a layout that would promote collaborative work. The ability to interact and collaborate was highly appreciated. Access to the projector screen would allow students to be able to project what they are working on, which would give them a sense of ownership of the learning process: they would be able to project the student tablet with the solution to the formula of a given problem to their fellow colleagues (the 'Inspiration HUB' in teachers' sandpit 3). In one sandpit, teachers suggested the use of colours for each sector of the space because this could help groups to work together and have a sense of group belonging. "The colours should be in the floor so that they are not a distracting factor. When speaking, the sector where the student is seated could be highlighted, creating an area visible to the other students so that the student speaking is clearly identified" (the 'Spheredome' in teachers' sandpit 1).

Students also felt that it would be very useful to be able to share and interact with the main projector using their tablets either through projection, the voting system or the twitter chat, which would be used to pose questions to the teacher. Similar findings were reported by Verdonck et al. (2019), who state that students appreciate how technology enables them to connect with the lecture without needing to physically leave their seat. Concerns were raised by teachers and students, however, about the real value of this type of interaction in a large 
space and suggestions were made about creating smaller and more-intimate spaces, such as the 'Sofa' and the 'Lilly pod' (Figures 5 and 6).

Figures 5 and 6 about here

Although we appreciate the need for smaller and more-intimate learning environments, we understand the importance of responding to the current marketisation of HE in which bigger spaces are needed to respond to the increased number of students per cohort. The challenge is how to make such spaces more interactive and collaborative for students to ensure their active participation in the learning process.

Alternatively, there were suggestions about changing the environment to one that is conducive to a flipped-classroom approach to teaching in which lecturing would be done online to give time for discussions in the classroom, as suggested by Goedhart et al. (2019) and by one of the 'Cube' 'sandpits' where a teacher said in relation to lecture capture: "Why don't we do this at home and share it using the VLE and do a flipped-classroom approach to teaching?" (teacher during sandpit 4).

Personal mobile devices

The use of tablets and tangible user interfaces in HE is a widely-researched topic in the learning technology community (Dillenbourg and Evans 2011; Mei and May 2018; Rossing et al. 2012). This research suggests that, although this technology is seen as having value for learning and teaching, there is still room to develop more-meaningful pedagogical resources and activities that match the potential of the technology (Mei and May 2018; Rossing et al. 2012). In the design of the two concepts, we decided to investigate teachers' and students' 
perceptions of tablets and mobile devices. In the 'Cube', we developed for the teacher a table-top touch screen which could be used for managing the slides and the projector screen, monitoring students' tablets and managing the room ambience. For all students, there was a 10-inch tablet embedded in the table to enable them to have their own desktop with their favourite applications by inserting their ID and password. In the 'Poppy Flower', the teachers used a simple tablet, whereas the students had access to a large table-top touch screen with the possibility of connecting to it with their own mobile devices. In both concepts, power outlets were easily accessible.

From the sandpits, we found that the students were very impressed by the role of the tablets in the two concepts. The possibility of being able to interact with the projector screen was highly praised because it gave them an opportunity to interact with the lecture and thus play a more-participative role. Concerns were raised in three 'sandpits' about the need for simplicity of access and the use of tangible user interfaces so that the setup could be as seamless as using a notepad. This is also reported by the research conducted by Mei and May (2018).

During students' sandpits, a large number of references were made to the ownership of mobile devices. The feeling from students was that institutional tablets should be utilised to support formal learning rather than personal smartphones or tablets. The rationale was that they would not like to amalgamate their personal interactions with family and friends with their study. In their opinion, because the two worlds needed to be separate, the use of customisable institutional tablets would provide a solution. They added that all devices should have a degree of personalisation, to enable them to have their own learning environment. Two of the student groups stated that they would lose the power outlets at every seat; by having power outlets, the learning space provides the message that students are being encouraged to use their own mobile devices in the classroom. Students stated that the use of 
personal devices would distract them because of the outside 'noise' caused by friends and family. Additionally, one group of students (the 'Knowledge Box' in students' sandpit 1) said that the use of tablets could be a perfect solution for the students for writing in their notebooks while they visualised the lecture on their tablet. The same group stated that tablets should be fixed to the table, but that the table should be able to be flipped to get a better look/experience. Furthermore, the tablet should be seven-inch, allowing a larger space for a notebook, which was still important for this group.

Contrary to the students' perceptions, the majority of the teacher groups suggested that students would prefer to use their own mobile devices because they are more familiar with them. This was supported by one teacher who said: "From my experience, because I think that they would use their own personal device more, what is the point of spending more money on technology if they are always on their phones?" (the 'Rose Bowl' in teachers' sandpit 2). Moreover, concerns were raised that the use of tablets to interact with the lecture would detract from the traditional question-and-answer method of teaching because the students would be too focused on the tablet rather than taking advantage of the physical environment. There was a sense in the teacher groups that excessive use of technology would jeopardise the exchange of opinions and views.

Our findings provided insights into the role of personal devices in learning environments because there was clearly a mismatch between the students' and the teachers' perceptions. The literature provides contrasting opinions about the ownership of tangible user interfaces (Raghunath et al. 2018; Šorgo et al. 2017). Although there appears to be a trend in which students bring their own device (BYOD) to learning environments, and there are arguments in favour of this, similar to those made by the teachers in this study, several studies refer to particular challenges around privacy, equity, technical support, network security and quality, and even possible classroom disruption (Aiyegbayo 2015; Santos 2013). 


\section{Discussion}

Participatory design sessions are engaging and creative environments where active users have the space to critique and redesign concepts with which they are involved on a daily basis. In this research, we aimed to foster discussions regarding TELE in HE by suggesting an exercise of redesigning two concepts of learning environments: the 'Cube' and the 'Poppy Flower'. Overall, students were more optimistic with the learning technologies suggested in the two concepts, particularly a customisable institutional tablet. They also provided insights into how they would like to connect with the lecture by using technology. They felt less comfortable with the large room because they would prefer smaller and more-collaborative rooms similar to the 'Poppy Flower'. Teachers were more critical towards learning technologies, with the data providing insights into the level of distrust felt by teachers when they need to use technology beyond a teacher-centred method (seen by them as the use of PowerPoint to project topics and guide lectures). These findings are important because they highlight levels of criticality from staff in relation to the use of learning technologies particularly in relation to their pedagogical value. This suggests that we should provide more guidance and pedagogical training to support staff in how to make the best use of learning technologies in the classroom (Beichner et al. 2000; van Merriënboer et al. 2017). We found that the assumption that students are always enthusiastic about all learning technologies was not always is the case (e.g. BYOD for learning). Better understanding of students and staff views about learning technologies in the classroom is likely to allow more-informed decisions and more-relevant use of learning technologies in the design of learning environments (Henderson et al. 2017; Waycott et al. 2010). 
We would also like to address the notion of physical learning environments in comparison with online learning environments. During the 'Sandpits', participants alluded to how would the virtual learning environment connects with the physical learning environment. At a time when online and blended learning are increasing as modes of delivery, one can ask about the value of traditional classrooms. The 'Sofa'and the 'Lilly Pod' (Figures 5 and 6) are examples of how teachers and students envision the learning environment of the future; these redesigns impact significantly in the roles that teachers and the students have in the learning process. Moreover, they seem to contradict the cabaret-style teaching being developed by the mainstream HE institutions and suggest more intimate learning experiences in which connectivity plays a paramount role. This is an area that we believe institutions should consider as learning becomes more ubiquitous.

In our research, we adopted an approach to learning environments design that mirrors some of the principles of active learning, which are based on dialogic encounters, discussion and experimentation, comparison of different mind-sets for learning purposes, sharing of power between different actors in the pedagogic process, and pattern-making as a form of effective learning. Aligning the principles of active learning with the process of designing learning environments seems essential in a truly user-centred more-democratic idea of HE governance. We used 'Sandpits' and the possibility of redesigning learning environments as tools to promote discussion about the role of learners and teachers in the teaching and learning process. The openness of the process, which started with a common design framework based on the presentation of the concepts and the narrative and finished with very different outputs, suggests that how participants see the learning environment design diverges according to their own individual views, which are informed by their own disciplinary practices, personal identities and institutional context. Therefore, it is conceivable that the outcomes of the research could be different for participants from different HE sectors or 
specific disciplines. However, being able to redesign a new environment based on a common framework was an opportunity for staff to engage in a creative grassroots process which would have been impossible if they have started with a finished prototype.

Acknowledging the value of this method for redesigning learning environments, we recognise that its blue-sky thinking approach is more suitable for a first iteration of the design process and as a way to engage stakeholders in thinking about their roles in learning and teaching. Equally, it could be a useful tool to generate new and creative learning environments more suitable for $21^{\text {st }}$ century pedagogy. In a second iteration, it is important to involve IT, estates and architects to evaluate what is achievable and sustainable.

This research was limited to one unique institution with its own particular policy and practices about learning and teaching. Therefore, further research comparing disciplinary and cultural perceptions of learning environments design would strengthen its findings.

Acknowledgements: The authors would like to thank Mr Paul Michel for his design interpretation of the new learning environments in Figures 5 and 6. 


\section{References}

Aiyegbayo, O. (2015). How and why academics do and do not use iPads for academic teaching? British Journal of Educational Technology, 46(6), 1324-1332.

Andrews, C., Endert, A., Yost, B., \& North, C. (2011). Information visualization on large, high-resolution displays: Issues, challenges, and opportunities. Information Visualization, 10(4), 341-355. https://doi.org/10.1177/1473871611415997

Baepler, P., Walker, J. D., \& Driessen, M. (2014). It's not about seat time: Blending, flipping, and efficiency in active learning classrooms. Computers \& Education, 78(3), 227236.

Barrett, P., Zhang, Y., Moffat, J., \& Kobbacy, K. (2013). A holistic, multi-level analysis identifying the impact of classroom design on pupils' learning. Building and Environment, 59, 678-689.

Beichner, R. J. (2014). History and evolution of active learning spaces. New Directions for Teaching and Learning, 2014(137), 9-16.

Beichner, R. J., Saul, J. M., Allain, R. J., Deardorff, D. L., \& Abbott, D. S. (2000). Introduction to SCALE-UP: Student-Centered Activities for Large Enrollment University Physics. Charlotte. http://eric.ed.gov/?id=ED459062

Bligh, B. (2014). Examining new processes for learning space design. In P. Temple (Ed.), The physical university: Contours of space and place in higher education (pp. 34-57). Oxon: Routledge.

Blin, F., \& Munro, M. (2008). Why hasn’t technology disrupted academics' teaching practices: Understanding resistance to change through the lens of activity theory. Computers \& Education, 50(2), 475-490. https://doi.org/10.1016/j.compedu.2007.09.017 
Bonsignore, E., Ahn, J., Clegg, T., Guha, M. L., Yip, J. C., \& Discussant, A. D. (2013). Embedding participatory design into designs for learning: An untapped interdisciplinary resource? Computer-Supported Cooperative Learning Conference (CSCL 2013). University of Wisconsin-Madison.

Boys, J. (2011). Towards creative learning spaces. Oxon, UK: Routledge.

Casanova, D., Di Napoli, R., \& Leijon, M. (2018). Which space? Whose space? An experience in involving students and teachers in space design. Teaching in Higher Education, 23(4), 488-503. https://doi.org/10.1080/13562517.2017.1414785

Cerratto-Pargman, T., Järvelä, S. M., \& Milrad, M. (2012). Designing Nordic technologyenhanced learning. The Internet and Higher Education, 15(4), 227-230. https://doi.org/10.1016/j.iheduc.2012.05.001

Clinton, V., \& Wilson, N. (2019). More than chalkboards: Classroom spaces and collaborative learning attitudes. Learning Environments Research, 22(3), 325-344.

Craft, B. (2013). Sketch-ins: A method for participatory design in technology-enhanced learning. In R. Luckin, S. Puntambekar, P. Goodyear, B. Grabowski, J. Underwood, \& N. Winters (Eds.), Handbook of design in ducational technology (pp. 92-101). Oxford: Routledge.

Crook, C., \& Mitchell, G. (2012). Ambience in social learning: Student engagement with new designs for learning spaces. Cambridge Journal of Education, 42(2), 121-139.

Dillenbourg, P., \& Evans, M. (2011). Interactive tabletops in education. International Journal of Computer-Supported Collaborative Learning, 6(4), 491-514. https://doi.org/10.1007/s11412-011-9127-7

Ebner, M., Lienhardt, C., Rohs, M., \& Meyer, I. (2010). Microblogs in higher education - A chance to facilitate informal and process-oriented learning? Computers \& Education, 55(1), 92-100. https://doi.org/10.1016/j.compedu.2009.12.006 
Fishman, B. J. (2013). Designing usable interventions: Bringing student perspectives to the table. Instructional Science, 42(1), 115-121. https://doi.org/10.1007/s11251-0139298-X

Frauenberger, C., Good, J., \& Keay-Bright, W. (2011). Designing technology for children with special needs: Bridging perspectives through participatory design. CoDesign, 7(1), 1-28. https://doi.org/http://dx.doi.org/10.1080/15710882.2011.587013

Frohlich, D. M., Lim, C. S. C., \& Ahmed, A. (2014). Keep, lose, change: Prompts for the redesign of product concepts in a focus group setting. CoDesign, 10(2), 80-95. https://doi.org/10.1080/15710882.2013.862280

Goedhart, N. S., Blignaut-van Westrhenen, N., Moser, C., \& Zweekhorst, M. B. M. (2019). The flipped classroom: Supporting a diverse group of students in their learning. Learning Environments Research, 22(2), 297-310.

Han, A. N. Y., Leong, L. C., \& Nair, P. K. (2014). X-space model: Taylor's university's collaborative classroom design and process. Procedia-Social and Behavioral Sciences, 123, 272-279.

Henderson, M., Selwyn, N., \& Aston, R. (2017). What works and why? Student perceptions of 'useful'digital technology in university teaching and learning. Studies in Higher Education, 42(8), 1567-1579.

James, K. E., Burke, L. A., \& Hutchins, H. M. (2006). Powerful or pointless? Faculty versus student perceptions of PowerPoint use in business education. Business Communication Quarterly, 69(4), 374-396.

Jamieson, P., Fisher, K., Gilding, T., Taylor, P. G., \& Trevitt, A. C. F. (2000). Place and space in the design of new learning environments. Higher Education Research and Development, 19(2), 221-236. https://doi.org/http://dx.doi.org/10.1080/072943600445664 
Janssen, F. J. J. M., Könings, K. D., \& van Merriënboer, J. J. G. (2017). Participatory educational design: How to improve mutual learning and the quality and usability of the design? European Journal of Education, 52(3), 268-279.

Jessop, T., Gubby, L., \& Smith, A. (2012). Space frontiers for new pedagogies: A tale of constraints and possibilities. Studies in Higher Education, 37(2), 189-202. https://doi.org/10.1080/03075079.2010.503270

JISC (Joint Information Systems Committee). (2006). Designing spaces for effective learning. Bristol: Author. http://www.jisc.ac.uk/media/documents/publications/learningspaces.pdf

Könings, K. D., Seidel, T., \& Merriënboer, J. J. G. (2014). Participatory design of learning environments: Integrating perspectives of students, teachers, and designers. Instructional Science, 42(1), 1-9. https://doi.org/10.1007/s11251-013-9305-2

Mäkelä, T., \& Helfenstein, S. (2016). Developing a conceptual framework for participatory design of psychosocial and physical learning environments. Learning Environments Research, 19(3), 411-440.

Mei, B., \& May, L. (2018). Reflective renovation: Insights from a collaborative and active learning space project evaluation. Australasian Journal of Educational Technology, $34(6), 12-18$.

Muller, M. J. (2007). Participatory design: The third space in HCI. In A. Sears, J. A. Jacko, \& J. A. Jackov (Eds.), The Human-computer interaction handbook (2 $2^{\text {nd }}$ ed., pp. 10701077). Boca Raton, FL: CRC Press.

Park, E. L., \& Choi, B. (2014). Transformation of classroom spaces: Traditional versus active learning classroom in colleges. Higher Education, 68(5), 749-771. https://doi.org/10.1007/s10734-014-9742-0

Raghunath, R., Anker, C., \& Nortcliffe, A. (2018). Are academics ready for smart learning? 
British Journal of Educational Technology, 49(1), 182-197.

Rossing, J. P., Miller, W. M., Cecil, A. K., \& Stamper, S. E. (2012). iLearning: The future of higher education? Student perceptions on learning with mobile tablets. Journal of the Scholarship of Teaching and Learning, 12(2), 1-26.

http://josotl.indiana.edu/article/view/2023

Santos, I. M. (2013). Key challenges associated with bringing personal mobile devices to the classroom. QScience Proceedings (12th World Conference on Mobile and Contextual Learning [mLearn 2013), 16.

Sheppard, S. D., Macatangay, K., Colby, A., \& Sullivan, W. M. (2008). Educating engineers: Designing for the future of the field (Vol. 2). San Francisco: Jossey-Bass.

Shupp, L., Andrews, C., Dickey-Kurdziolek, M., Yost, B., \& North, C. (2009). Shaping the display of the future: The effects of display size and curvature on user performance and insights. Human-Computer Interaction, 24(1-2), 230-272.

Šorgo, A., Bartol, T., Dolničar, D., \& Boh Podgornik, B. (2017). Attributes of digital natives as predictors of information literacy in higher education. British Journal of Educational Technology, 48(3), 749-767.

Temple, P. (2008). Learning spaces in higher education: an under- researched topic. London Review of Education, 6(3), 229-241.

https://doi.org/https://doi.org/10.1080/14748460802489363

van Merriënboer, J. J. G., McKenney, S., Cullinan, D., \& Heuer, J. (2017). Aligning pedagogy with physical learning spaces. European Journal of Education, 52(3), 253267.

Van Note Chism, N. (2006). Challenging traditional assumptions and rethinking learning spaces. In D. G. Oblinger (Ed.), Learning spaces. Washington, DC: Educause.

Verdonck, M., Greenaway, R., Kennedy-Behr, A., \& Askew, E. (2019). Student experiences 
of learning in a technology-enabled learning space. Innovations in Education and Teaching International, 56(3), 270-281.

Waycott, J., Bennett, S., Kennedy, G., Dalgarno, B., \& Gray, K. (2010). Digital divides? Student and staff perceptions of information and communication technologies. Computers \& Education, 54(4), 1202-1211. 


\section{List of figures}

Fig. 1 Footprint of the 'Cube' seen from the top

Fig. 2 Overview of the 'Cube' podium and table top tablet

Fig. 3 Footprint of the 'Poppy Flower' seen from the top

Fig. 4 Footprint of the 'Poppy Flower' with details of how technology would work for each table

Fig. 5 Footprint of the 'Sofa' redesign proposal from teachers in sandpit 4

Fig. 6 Footprint of the 'Lilly Pod' redesign proposal from students in sandpit 4 


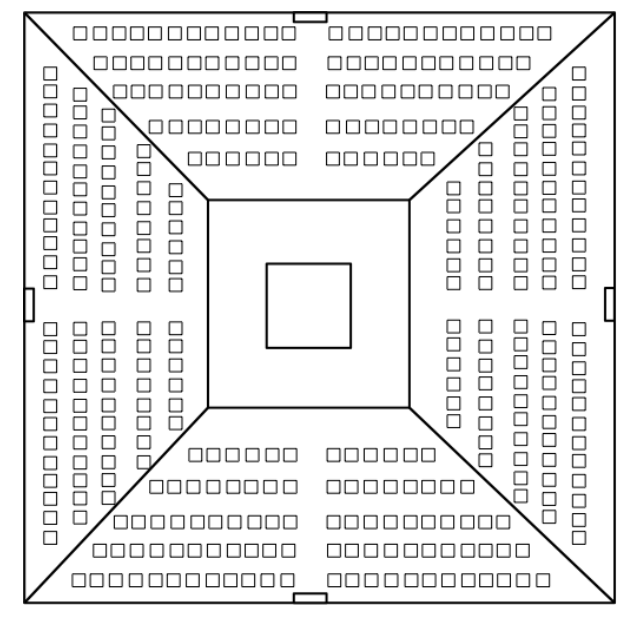

Fig. 1

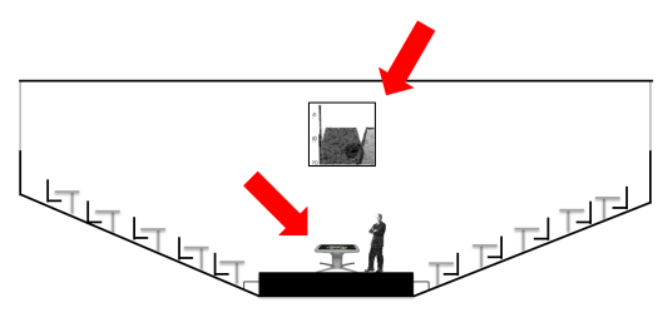

Fig. 2 


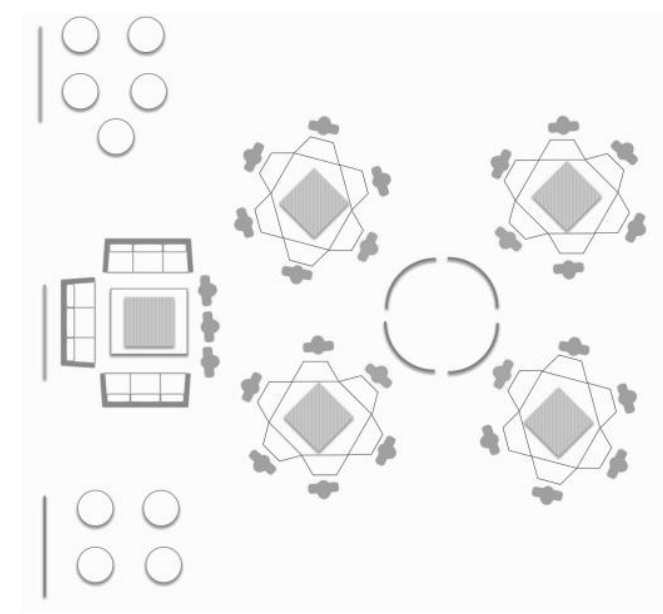

Fig. 3

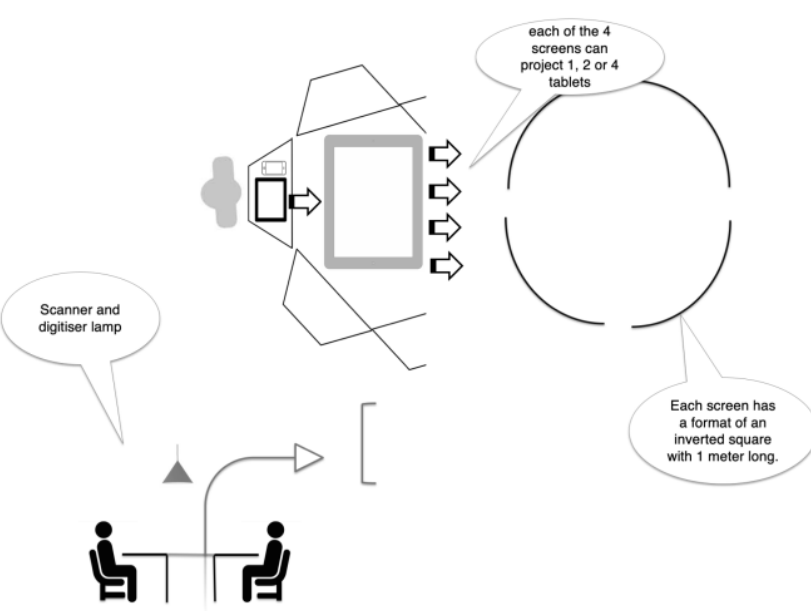

Fig. 4 


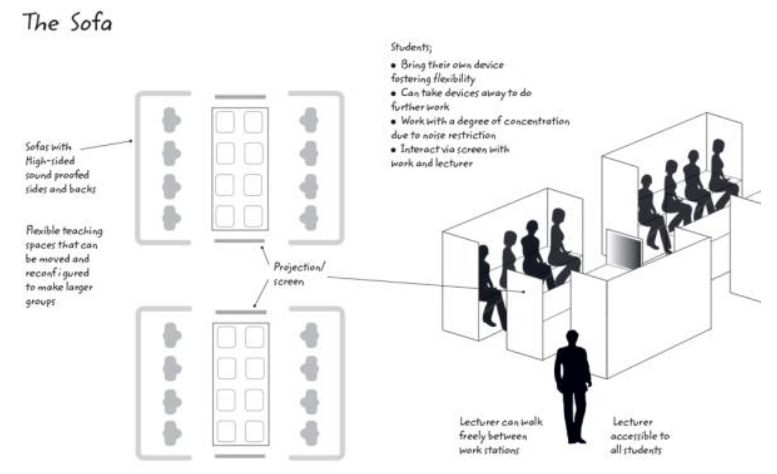

Fig. 5

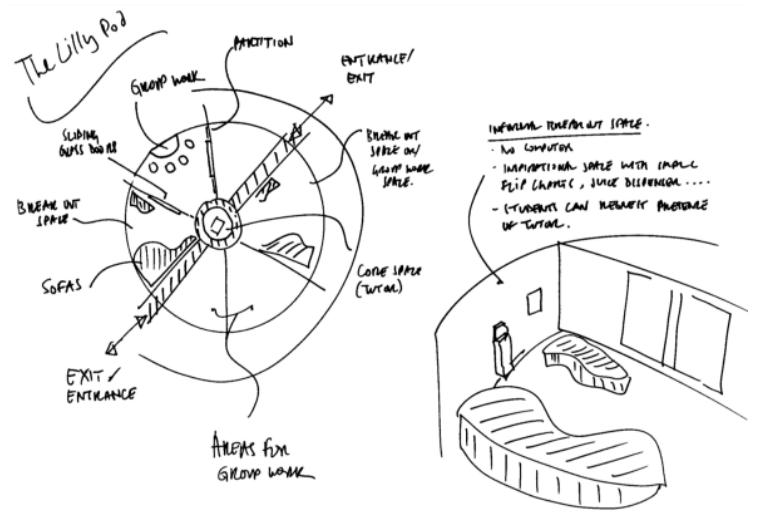

Fig. 6 
Table 1 Sandpits, names given to final concept and number of instances by technology theme

\begin{tabular}{|c|c|c|c|c|c|}
\hline Sandpit & Concept & $\begin{array}{l}\text { Name given to } \\
\text { space }\end{array}$ & Visualisation & $\begin{array}{l}\text { Personal } \\
\text { mobile } \\
\text { devices }\end{array}$ & $\begin{array}{l}\text { Interaction and } \\
\text { collaboration }\end{array}$ \\
\hline Teachers sandpit 1 & Cube & Spheredome & 7 & 1 & 4 \\
\hline Teachers sandpit 2 & Cube & Rose Bow & 5 & 4 & 3 \\
\hline Teachers sandpit 3 & Cube & Inspiration Hub & 2 & 2 & 3 \\
\hline Teachers sandpit 4 & Cube & Sofa & 2 & 4 & 8 \\
\hline Teachers sandpit 5 & Cube & Shape Shifter & 5 & 3 & 7 \\
\hline Teachers sandpit 6 & Poppy-Flower & Hollodock & 6 & 4 & 3 \\
\hline Teachers sandpit 7 & Poppy-Flower & The Pub & 2 & 3 & 6 \\
\hline Student sandpit 1 & Cube & Knowledge Box & 3 & 4 & 3 \\
\hline Student sandpit 2 & Cube & The Dome & 2 & 2 & 6 \\
\hline Student sandpit 3 & Cube & Horseshoe & 1 & 0 & 8 \\
\hline Student sandpit 4 & Poppy-Flower & Lilly Pod & 5 & 2 & 4 \\
\hline Student sandpit 5 & Poppy-Flower & Pizza Room & 3 & 4 & 6 \\
\hline Student sandpit 6 & Poppy-Flower & The Hub & 4 & 2 & 5 \\
\hline
\end{tabular}

